http://jmscr.igmpublication.org/home/

ISSN (e)-2347-176x ISSN (p) 2455-0450

crossref DOI: https://dx.doi.org/10.18535/jmscr/v8i12.01

\title{
Comparison of Refractive Errors between Urban and Rural School Going Children
}

\author{
Authors \\ Shiraz Ahmad Bhat ${ }^{1}$, Ajay Kumar Saxena', Vijender Kour ${ }^{3}$
}

\begin{abstract}
Purpose: To compare Spectrum of refractive errors in Urban and Rural School going children.

Material and Methods: A total of 100 children between 6-16 years of age were included in this study (50 rural and 50 urban). Refractive errors were calculated and compared between the two groups.

Results: Out of 100 children 22\% were in the age group of 6-8 years, $30 \%$ in the age group of 9-11 years with a frequency of $30 \%$ and $34 \%$ in the age group of $12-14$ years and $14 \%$ of $\geq 15$ years. The mean age was 11.2 years. Out of 100 patients uncorrected visual acuity between $6 / 6$ to $6 / 12$ was $51 \%$ in right eye and $48 \%$ in left eye. Visual acuity between $6 / 18$ to $6 / 24$ was $27 \%$ in right eye and $30 \%$ in left eye. Visual acuity $6 / 36$ was $15 \%$ in right eye and $14 \%$ in left eye. Visual acuity worse than $6 / 36,7 \%$ in right eye and $8 \%$ in left eye. Out of 100 children majority of patients are hypermetropia of $61.3 \%$ with refractive errors of 2-6D and more than $6 D$, majority are myopic $(19.5 \%)$ and less than $2 D$ are myopic astigmatism. Frequency of anisometropia more than $1.5 \mathrm{D}$ was $20 \%$ and less than $1.5 \mathrm{D}$ was $80 \%$. Myopia was more common in urban (52\%) followed by hyperopia (26\%) whereas hyperopia was more common in rural (36\%).

Conclusion: We concluded from this study that refractive error is one of the most common causes of visual impairment. Myopia is the commonest refractive error in school going children, which is slightly higher in urban children due to indoor games and use of computers and video games. Hypermetropia is the most common cause of refractive error in children of rural area.
\end{abstract}

\section{Introduction}

Refractive error is the second leading cause of treatable blindness and one of the most common causes of visual impairment in school going children ${ }^{1}$.

As per the estimates across the globe, 2.3 billion people have refractive errors; out of these 1.8 billion people have eye care facilities at affordable cost. The remaining 500 million have no significant eye care services and are living in developing countries. These mainly include children $^{2,3}$. In Indian school going children, refractive error is the second most common eye problem.

Visual impairment in children is an important cause for poor performance in studies, inability to actively participate in sports and other cultural activities. This leads to the development of an inferiority complex and increased school dropouts. This can be reduced by an early detection of refractive errors in school children through screening. Uncorrected refractive errors are responsible for as much as $19.7 \%$ of blindness. About $13 \%$ of the Indian population is in the age 
group of 7-15 years and about $20 \%$ children develop refractive error by the age of 16 years ${ }^{4}$. Considering the importance of this common eye problem we took this topic to study the school going children in urban and rural parts of Uttar Pradesh, India.

\section{Material and Methods}

This study was carried out at a tertiary eye care hospital in northern India from February 2019 to November 2019.A total of 100 children were studied (50 rural and 50 urban).Patients of both sex aged 6-16 years were included in this study.

\section{Results}

Out of 100 children $22 \%$ were in the age group of 6-8 years, $30 \%$ in the age group of 9-11 years with a frequency of $30 \%$ and $34 \%$ in the age group of $12-14$ years and $14 \%$ of $\geq 15$ years. The mean age was 11.2 years.

Out of 100 patients uncorrected visual acuity between $6 / 6$ to $6 / 12$ was $51 \%$ in right eye and $48 \%$ in left eye. Visual acuity between $6 / 18$ to $6 / 24$ was $27 \%$ in right eye and $30 \%$ in left eye. Visual acuity $6 / 36$ was $15 \%$ in right eye and $14 \%$ in left eye. Visual acuity worse than $6 / 36,7 \%$ in right eye and $8 \%$ in left eye. Out of 100 children majority of patients are hypermetropia of $61.3 \%$ with refractive errors of 2-6D and more than $6 \mathrm{D}$, majority are myopic (19.5\%) and less than 2D are myopic astigmatism (Table-1). Frequency of anisometropia more than $1.5 \mathrm{D}$ was $20 \%$ and less than $1.5 \mathrm{D}$ was $80 \%$. Myopia was more common in urban (52\%) followed by hyperopia (26\%) whereas hyperopia was more common in rural (36\%) (Table-2).

\begin{tabular}{|c|c|c|c|c|c|c|c|}
\hline \multirow[t]{2}{*}{ Eye } & \multirow[t]{2}{*}{ Error } & \multicolumn{2}{|c|}{ < 2 Diopters } & \multicolumn{2}{|c|}{ 2-6 Diopters } & \multicolumn{2}{|c|}{ > 6 Diopters } \\
\hline & & No. & \%age & No. & \%age & No. & \%age \\
\hline \multirow{3}{*}{ Right Eye } & Myopia & 18 & 43.9 & 15 & 36.6 & 8 & 19.5 \\
\hline & Hypermetropia & 11 & 35.5 & 17 & 54.8 & 3 & 9.7 \\
\hline & Astigmatism & 8 & 44.4 & 7 & 38.9 & 3 & 16.7 \\
\hline \multirow[t]{3}{*}{ Left Eye } & Myopia & 17 & 41.5 & 16 & 39.0 & 8 & 19.5 \\
\hline & Hypermetropia & 10 & 32.3 & 19 & 61.3 & 2 & 6.5 \\
\hline & Astigmatism & 9 & 50.0 & 6 & 33.3 & 3 & 16.7 \\
\hline
\end{tabular}

\begin{tabular}{|l|c|c|c|c|}
\hline \multicolumn{3}{|c|}{ Table 2: Distribution of refractive errors as per residence } \\
\hline \multirow{2}{*}{ Refractive Error } & \multicolumn{2}{|c|}{ Rural } & \multicolumn{2}{c|}{ Urban } \\
\cline { 2 - 5 } & No. & \%age & No. & \%age \\
\hline Myopia & 15 & 30 & 26 & 52 \\
\hline Hypermetropia & 18 & 36 & 13 & 26 \\
\hline Astigmatism & 11 & 22 & 7 & 14 \\
\hline Anisometropia & 6 & 12 & 4 & 8 \\
\hline Total & 50 & 100 & 50 & 100 \\
\hline
\end{tabular}

\section{Discussion}

Uncorrected refractive errors are an important cause of blindness and visual impairment in many countries (Dandona $L$ et al 1998). In developing countries however, it is often difficult to provide efficient refraction services for a variety of reasons, and this results in a high prevalence of uncorrected refractive errors in these regions. Avoidable blindness and low vision can restrict progress in education, limit motor development in children, affect mobility, limit career opportunities and restrict access to information. It is a burden on the community and its social and income generating services. So there is a priority need to control and prevent these disorders. He Met al ${ }^{5}$ found that Myopia (spherical equivalent of at least-0.50D in either eye) measured with retinoscopy affected $73.1 \%$ of children of 15 years of age. Hyperopia (+2.00D or more) measured retinoscopy was present in $16.7 \%$ of 5 year old. 
Astigmatism (cylinder of $\geq 0.75 \mathrm{D}$ ) was present in $33.6 \%$ of children, he found prevalence of reduced vision due to myopia is high in urban children. In our study we found myopia of more than $-0.50 \mathrm{D} 43.9 \%$ in right eye and $41.5 \%$ in left eye. Hyperopia of more than $+0.50 \mathrm{D}, 35.5 \%$ in right eye and $32.3 \%$ in left eye, we also found that prevalence of myopia is high in urban children. Yoon KC, et al $^{6}$ Conducted a study and found prevalence of myopia, hyperopia, astigmatism and strabismus in participants over 3 years of age was $53.7 \pm 0.6 \%, 10.7 \pm 0.4 \%, 58.0 \pm 0.6 \%$ and $1.5 \pm 0.1 \%$ respectively. In our study we found prevalence of myopia, hyperopia, astigmatism and strabismus in participants over 6 years of age was $41 \%, 31 \%$, $18 \%$ and $9 \%$ respectively. Lim HT et al $^{7}$ conducted a study to evaluate the sociodemographic factors of myopia in Korean children. The prevalence of child myopia in Korea was $22.6 \%$. Participants living in homes owned by their parents or in urban areas were more likely to have myopia. In our study we compared refractive errors between rural and urban school going children were we found prevalence of myopia was high in urban $(52 \%)$ in comparison to rural which was only (30\%) Ghosh $\mathbf{S}$, et $\mathbf{a l}^{\mathbf{8}}$ conducted a study on 2570 children, myopia and hyperopia was present in 307 and 65 children respectively. Visual acuity of less than $6 / 12$ in better eye was present in 109 children, 18 children had amblyopia. In our study of 100 children of refractive errors myopia and hyperopia was present in 41 and 31 children respectively. Visual acuity of less than $6 / 12$ in better eye was present in 40 children, 17 children had amblyopia.

\section{Conclusion}

We concluded from this study that refractive error is one of the most common causes of visual impairment. Myopia is the commonest refractive error in school going children, which is slightly higher in urban children due to indoor games and use of computers and video games. Hypermetropia is the most common cause of refractive error in children of rural area.

\section{Bibliography}

1. Murthy GVS, Gupta SK, Ellwein LB, et al. Refractive error in children in an urban population in New Delhi. Invest Ophthalmol Vis Sci 2002;43:623-31.

2. Niroula DR, Saha CG. Study on the refractive errors of school going children of Pokhara city in Nepal. Kat Uni Med J. 2009;7(1):67-72.

3. Khan N, Jangir M, Kochar A, Bhargava P. Prevalence of refractive error among school children in North-West Rajasthan. Inter J Biomed and Adv Res. 2016;7 (12):565-68.

4. Pavithra MB, Maheshwaran R, Sujatha R. A study on the prevalence of refractive errors among school children of 7-15 years age group in the field practice areas of a medical college in Bangalore. Int $\mathrm{J}$ Med Sci Pub Health 2013; 2:641-45.

5. He M, Zeng J, Liu Y, Xu, J, Pokharel GP, et al. Refractive error and visual impairment in urban children China. Invest Ophthalmol Vis Sci. 2004; 45: 793-799.

6. Yoon KC, Mim GH, Kim SD, Kim SH, Kim CY et al. Prevalence of eye diseases in South Korea: data from the Korea National Health and Nutrition Examination Survey 2008-2009. Korean J Ophthalmol. 2011; 25: 421-433.

7. Lim HT, Yoon JS, Hwang SS, Lee SY. Prevalence and associated sociodemographic factors of myopia in Korean children: the 2005 third Korea Natioanl Health and Nutrition Examination Survey (KNHANES III). Jap J Ophthalmol. 2012; 56:76-81.

8. Ghosh S, Mukhopadhyay U, Maji D, Bhaduri G. Visual impairment in urban school children of low income families in Kolkata, India.Indian J Public Health. 2012; 56(2): 163-67. 